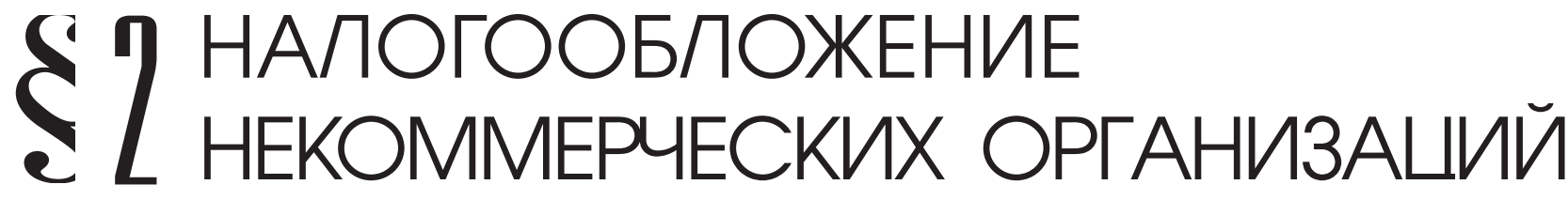

Козлова С.A.

\section{НАЛОГООБЛОЖЕНИЕ ПЛАТНОЙ ОБРАЗОВАТЕЛЬНОЙ ДЕЯТЕЛЬНОСТИ И ПРИНОСЯЩЕЙ ДОХОД ДЕЯТЕЛЬНОСТИ ОБРАЗОВАТЕЛЬНЫХ УЧРЕЖДЕНИЙ}

Аннотация: Реформа сочиальной сферы призвана упорядочить в том числе налогообложение от платной образовательной деятельности и приносящей доход деятельности образовательных учреждений. До реформирования системы государственных, в том числе образовательных учреждений не был однозначно решен вопрос о том, могли ли образовательныле учреждения самостоятельно распорядиться «заработанными средствами» и надо ли было с них платить налоги в бюджет. В статье проводиться разграничение платной образовательной деятельности и приносящей доход деятельности образовательных учреждений

Review: The social reform is aimed to harmonize taxation from paid educational activities and profitable activities of educational institutions. Prior to the reform of state educational institutions, the issues of whether the educational institutions have the right to use the money, which they have earned, and whether they need to pay taxes, were not resolved. The article distinguishes between paid educational activities and profitable activities of educational institutions.

Ключевые слова: Налоги и налогообложение, казенное учреждение, бюджетное учреждение, автономное учреждение, налог на прибыль организаций, налог на добавленную стоимость, налог на имущеество организаций, земельный налог, упрощенная система налогообложения, традиционная система налогообложения

Keywords: taxes and taxation, fiscal institution, budget institution, autonomous institution, tax on profit of organizations, value added tax, tax on property of organizations, land tax, simplified taxation system, traditional taxation system.

\section{1. Общие положения.}

едеральный закон 8 мая 2010 г. «О внесении изменений в отдельные законодательные акты Российской Федерации в связи с совершенствованием правового положения государственных (муниципальных) учреждений» [1] призван сформировать основу законодательной базы для развития новых форм финансового обеспечения государственных (муниципальных) услуг. В соответствии с Законом «Об образовании» [2], образовательные учреждения могут быть государственными, муниципальными, негосударственными (частными учреждениями, в том числе учреждениями общественных объединений и религиозных организаций). 
Государственным является образовательное учреждение, созданное Российской Федерацией или субъектом Российской Федерации. Муниципальным является образовательное учреждение, созданное муниципальным образованием.

Негосударственным является образовательное учреждение, созданное в соответствии с Законом «Об образовании» собственником (гражданином (гражданами) и (или) юридическим лицом (юридическими лицами), за исключением Российской Федерации, субъектов Российской Федерации и муниципальных образований.

Бюджетным учреждением признается некоммерческая организация, созданная Российской Федерацией, субъектом Российской Федерации или муниципальным образованием для выполнения работ, оказания услуг в целях обеспечения реализации предусмотренных законодательством Российской Федерации полномочий соответственно органов государственной власти (государственных органов) или органов местного самоуправления в сферах науки, образования, здравоохранения, культуры, социальной защиты, занятости населения, физической культуры и спорта, а также в иных сферах (ст.9.2 Федерального закона от 12 января 1996 года N 7-Ф3 «О некоммерческих организациях»).

Казенное учреждение - государственное (муниципальное) учреждение, осуществляющее оказание государственных (муниципальных) услуг, выполнение работ и (или) исполнение государственных (муниципальных) функций в целях обеспечения реализации предусмотренных законодательством Российской Федерации полномочий органов государственной власти (государственных органов) или органов местного самоуправления, финансовое обеспечение деятельности кото- рого осуществляется за счет средств соответствующего бюджета на основании бюджетной сметы (абзац 39 ст. 6 БК РФ).

Автономным учреждением признается некоммерческая организация, созданная Российской Федерацией, субъектом Российской Федерации или муниципальным образованием для выполнения работ, оказания услуг в целях осуществления предусмотренных законодательством Российской Федерации полномочий органов государственной власти, полномочий органов местного самоуправления в сферах науки, образования, здравоохранения, культуры, социальной защиты, занятости населения, физической культуры и спорта, а также в иных сферах в случаях, установленных федеральными законами.

Финансовое обеспечение образовательной деятельности федеральных государственных казенных учреждений и финансовое обеспечение выполнения государственного задания государственными бюджетными и автономными образовательными учреждениями осуществляются на основе федеральных нормативов финансового обеспечения образовательной деятельности.

В соответствии со ст. 78.1 БК РФ в бюджетах бюджетной системы Российской Федерации предусматриваются субсидии бюджетным и автономным учреждениям на возмещение нормативных затрат, связанных с оказанием ими в соответствии с государственным (муниципальным) заданием государственных (муниципальных) услуг (выполнением работ).

Из бюджетов бюджетной системы Российской Федерации могут предоставляться субсидии бюджетным и автономным учреждениям на иные цели.

Особенности правового положения казенных учреждений состоят в том, что казенное учреждение находится в ведении органа 
DOI: $10.7256 / 1812-8688.2013 .9 .4561$

При цитировании этой статьи сноска на доі обязательна

\section{Налоги и налогообложение - №9(111) • 2013}

государственной власти (государственного органа), органа местного самоуправления, осуществляющего бюджетные полномочия главного распорядителя (распорядителя) бюджетных средств.

Образовательные учреждения вправе оказывать платные образовательные услуги, а также вести приносящую доход деятельность.

Каковы правовые, в том числе гражданскоправовые и налоговые последствия, ведения платной образовательной деятельности и приносящей доход деятельности?

В соответствии с «Об образовании» образовательные государственные учреждения вправе оказывать населению, предприятиям, учреждениям и организациям платные дополнительные образовательные услуги (обучение по дополнительным образовательным программам, преподавание специальных курсов и циклов дисциплин, репетиторство, занятия с обучающимися углубленным изучением предметов и другие услуги), не предусмотренные соответствующими образовательными программами и федеральными государственными образовательными стандартами, а также образовательными стандартами (ст. 45).

Негосударственное образовательное учреждение вправе взимать плату с обучающихся, воспитанников за образовательные услуги, в том числе за обучение в пределах федеральных государственных образовательных стандартов или федеральных государственных требований. При этом платная образовательная деятельность такого образовательного учреждения не рассматривается как предпринимательская, если получаемый от нее доход полностью идет на возмещение затрат на обеспечение образовательного процесса (в том числе на заработную плату), его развитие и совершенствование в данном образовательном учреждении (ст.46).
Как следует из статьи 47 Закона об образовании и образовательное государственное учреждение и негосударственное образовательное учреждение вправе вести приносящую доход деятельность, предусмотренную его уставом постольку, поскольку это служит достижению целей, ради которых они созданы, и соответствует указанным целям.

Приносящая доход деятельность государственными и муниципальными образовательными учреждениями допускается, если это не противоречит федеральным законам.

С 1 января 2011 года до 1 июля 2012 года установлен переходный период, в течение которого на деятельность, приносящую доход, распространяются следующие правила;

- для казенных и бюджетных учреждений установлено, что приносящая доход деятельность производится на основании документа (генерального разрешения) главного распорядителя (распорядителя) бюджетных средств, в котором указываются источники образования и направления использования средств;

- бюджетное учреждение, являющееся получателем бюджетных средств, или казенное учреждении осуществляет операции с внебюджетными средствами в установленном Минфином России порядке в соответствии со сметой доходов и расходов по приносящей доходы деятельности, подлежащей представлению в орган, осуществляющей открытие и ведение лицевого счета (орган Федерального казначейства).

В 2011 году необходимо утвердить смету доходов и расходов по приносящей доход деятельности (данная смета, как и разрешение, является основанием для открытия и ведения лицевого счета).

Кроме того, для отражения на соответствующих лицевых счетах учреждений, являющихся получателями бюджетных средств, 
и казенных учреждений операции с внебюджетными средствами применяются единая для бюджетов бюджетной системы РФ группа доходов бюджетов «Доходы от приносящей доходы деятельности» и входящие в нее следующие подгруппы группы:

а) доходы от собственности по приносящей доходы деятельности;

б) рыночные продажи товаров и услуг;

в) безвозмездные поступления от приносящей доходы деятельности;

г) целевые отчисления от государственных и муниципальных лотерей.

В 2011 году, оказывая услуги (выполняя работы) в рамках внебюджетной деятельности, необходимо руководствоваться нормами приказа Минфина России от 1 сентября 2008 г. № 88н «О Порядке осуществления федеральными казенными учреждениями операций со средствами, полученными от приносящей доход деятельности». Следует учесть, что нормы данного приказа действуют до 1 января 2012 года. Его положения распространяются не только на казенные учреждения, но и на бюджетные учреждения, в отношении которых органами исполнительной власти - главными распорядителями средств - не принято решение о предоставлении им субсидий из федерального бюджета в соответствии с пунктом 1 статьи 78.1 Бюджетного кодекса РФ.

Определен порядок оформления разрешений на осуществление предпринимательской и иной приносящей доход деятельности по типовым формам:

- форма 0531735 - Разрешение на осуществление приносящей доход деятельности;

- форма 0531736 - Дополнение к Разрешению на осуществление приносящей доход деятельности.

С 1 января 2012 года бюджетными и автономными учреждениями вместо сметы будет составляться План финансово-хозяйственной деятельности в соответствии с приказом Минфина России от 28 июля 2010 №81н.

Плановые показатели будут формироваться учреждением в разрезе поступлений от оказания услуг, относящихся в соответствии с уставом учреждения к его основным видам деятельности, предоставление которых для физических и юридических лиц осуществляется на платной основе, а также поступлений от иной приносящей доход деятельности. План бюджетного учреждения утверждается органом, осуществляющим функции и полномочия учредителя.

План автономного учреждения утверждается руководителем автономного учреждения на основании заключения наблюдательного совета автономного учреждения.

Итак, законодатель четко разделяет образовательные услуги и прочие услуги. Для образовательных услуг характерно, прежде всего то, что образовательную деятельность может осуществлять только субъект, обладающий соответствующими профессиональными знаниями, умениями, навыками, которые соответствуют федеральным государственным образовательным стандартам и подтверждены документом установленной формы, подтверждающим достижение лицом установленных государством уровней образования (образовательных цензов) и (или) квалификации.

Образовательные услуги - профессиональная деятельность управомоченного лица, направленная на передачу обучающимся образовательных программ или программ отдельных учебных курсов, предметов, дисциплин (модулей), и предполагающая интеллектуальную деятельность обучающихся, направленную на освоение знаний, умений, навыков, подтвержденных соответствующим образовательным цензом, дающим право на продолжение обра- 
DOI: $10.7256 / 1812-8688.2013 .9 .4561$

При цитировании этой статьи сноска на доі обязательна

\section{Налоги и налогообложение - №9(111) • 2013}

зования на следующем уровне и/или занятие профессиональной деятельностью.

Платные образовательные услуги не могут быть оказаны вместо образовательной деятельности, финансируемой за счет средств бюджета. В противном случае средства, заработанные посредством такой деятельности, изымаются учредителем в его бюджет (п. 3 ст. 45 «Закона об образовании»).

Основными нормативными документами, регулирующими отношения между образовательными учреждениями и потребителями (учащимися, воспитанниками и их родителями, выступающими в качестве покупателей, юридическими лицами), являются Гражданский кодекс, Закон «Об образовании», Правила оказания платных образовательных услуг утв., Постановлением Правительства Российской Федерации от 5 июля 2001 г. N 505.

Договор заключается в письменной форме и в соответствии с Правилами оказания платных образовательных услуг. Минобразования утверждены примерные формы Договора об оказании платных образовательных услуг, договор должен быть заключен по определенной форме.

При осуществлении иных видов приносящей доход деятельности заключаются договоры о возмездном оказании услуг.

Согласно ст. 450 ГК РФ договор может быть изменен или расторгнут по соглашению сторон, решению суда (при существенном нарушении договора; при существенном изменении обстоятельств или в иных случаях, предусмотренных законодательством или договором).

В случае изменения условий договора обязательства сторон сохраняются, но в ином виде, а при расторжении - прекращаются. Обязательства считаются измененными или прекращенными с момента заключения согла- шения, если иное не вытекает из соглашения или характера изменения договора, либо с момента вступления в законную силу решения суда (ст. 453 ГК РФ).

Казенное учреждение может осуществлять приносящую доходы деятельность, только если такое право предусмотрено в его учредительном документе. Доходы, полученные от указанной деятельности, поступают в соответствующий бюджет бюджетной системы Российской Федерации (ст.161 Бюджетного кодекса РФ).

Таким образом, осуществление образовательной деятельности в отличии от иной приносящей доход деятельности связано с наличием специальной правоспособности.

\section{2. Налог на прибыль организаций.}

Для целей налогообложения различные виды доходов отражаются одинаково. Образовательные учреждения являются плательщиками налога на прибыль.

С 1 января 2011 года в соответствии с пунктом 5 статьи 16 Федерального закона от 8 мая 2010 г. №83 -Ф3 статья 321.1 «Особенности ведения налогового учета бюджетными учреждениями» утратила силу. Следовательно, учреждениям (казенным, бюджетным, автономным) придется разработать систему налогового учета для определения налога на прибыль (по приносящей доход деятельности) в соответствии с общими принципами, установленными главой 25 «Налог на прибыль организаций».

С 1 января 2011 года действует статья 284.1 Налогового кодекса РФ устанавливающая особенности применения налоговой ставки 0 процентов организациями, осуществляющими образовательную деятельность.

Положения статьи 284.1 применяются с 1 января 2011 года до 1 января 2020 года, 
статья введена Федеральным законом от 28.12.2010 N 395-Ф3.

Так, организации, осуществляющие образовательную деятельность в соответствии с законодательством Российской Федерации, вправе применять налоговую ставку 0 процентов при соблюдении условий, установленных статьей 284.1 Налогового кодекса РФ.

Для целей указанной статьи образовательной признается деятельность, включенная в Перечень видов образовательной деятельности, установленный Правительством Российской Федерации;

Налоговая ставка 0 процентов применяется организациями, осуществляющими образовательную деятельность, ко всей налоговой базе, определяемой такими налогоплательщиками (за исключением налоговой базы, налоговые ставки по которой установлены пунктами 3 и 4 статьи 284 Налогового кодекса РФ), в течение всего налогового периода.

Организации, вправе применять налоговую ставку 0 процентов, если они удовлетворяют следующим условиям:

1) если организация имеет лицензию (лицензии) на осуществление образовательной деятельности, выданную (выданные) в соответствии с законодательством Российской Федерации;

2) если доходы организации за налоговый период от осуществления образовательной деятельности, а также от выполнения научных исследований и (или) опытно-конструкторских разработок, учитываемые при определении налоговой базы, составляют не менее 90 процентов ее доходов, учитываемых при определении налоговой базы, либо если организация за налоговый период не имеет доходов, учитываемых при определении налоговой базы;

3) если в штате организации непрерывно в течение налогового периода числятся не менее 15 работников;
4) если организация не совершает в налоговом периоде операций с векселями и финансовыми инструментами срочных сделок.

При несоблюдении организациями, хотя бы одного из условий из вышеперечисленных условий с начала налогового периода, в котором имело место несоблюдение указанных условий, применяется налоговая ставка, установленная пунктом 1 статьи 284 Налогового кодекса РФ. При этом сумма налога подлежит восстановлению и уплате в бюджет в установленном порядке с уплатой соответствующих пеней, начисляемых со дня, следующего за установленным статьей 287 Кодекса днем уплаты налога (авансового платежа по налогу).

Организации, изъявившие желание применять налоговую ставку 0 процентов, не позднее чем за один месяц до начала налогового периода, начиная с которого применяется налоговая ставка 0 процентов, подают в налоговый орган по месту своего нахождения заявление, копии лицензии (лицензий) на осуществление образовательной, выданной (выданных) в соответствии с законодательством Российской Федерации.

Организации, применяющие налоговую ставку 0 процентов, по окончании каждого налогового периода, в течение которого они применяют налоговую ставку 0 процентов, в установленные сроки для представления налоговой декларации, представляют в налоговый орган по месту своего нахождения следующие сведения:

- о доле доходов организации от осуществления образовательной деятельности, учитываемых при определении налоговой базы, в общей сумме доходов организации;

- о численности работников в штате организации.

Бюджетные учреждения, равно как и автономные, вправе уплачивать только квартальные 
DOI: $10.7256 / 1812-8688.2013 .9 .4561$

При цитировании этой статьи сноска на доі обязательна

\section{Налоги и налогообложение - №9(111)•2013}

авансовые платежи по налогу на прибыль по итогам отчетного периода (п.3 ст. 286 НК РФ).

\section{Налог на добавленную стоимость.}

В силу пп. 1 п. 1 ст. 146 Налогового кодекса РФ объектом налогообложения по налогу на добавленную стоимость (НДС) признается реализация товаров (работ, услуг) на территории Российской Федерации, в том числе реализация предметов залога и передача товаров (результатов выполненных работ, оказания услуг) по соглашению о предоставлении отступного или новации, а также передача имущественных прав.

Не подлежит налогообложению (освобождается от налогообложения) реализация (а также передача, выполнение, оказание для собственных нужд) на территории Российской Федерации услуг в сфере образования по проведению некоммерческими образовательными организациями учебно-производственного (по направлениям основного и дополнительного образования, указанным в лицензии) или воспитательного процесса, за исключением консультационных услуг, а также услуг по сдаче в аренду помещуений (пп. 14 п. 2 ст. 149 НК РФ).

Реализация некоммерческими образовательными организациями товаров (работ, услуг) как собственного производства (произведенных учебными предприятиями, в том числе учебно-производственными мастерскими, в рамках основного и дополнительного учебного процесса), так и приобретенных на стороне подлежит налогообложению вне зависимости от того, направляется ли доход от этой реализации в данную образовательную организацию или на непосредственные нужды обеспечения развития, совершенствования образовательного процесса.
Исходя из п. 6 ст. 149 НК РФ, перечисленные операции не подлежат налогообложению при наличии у налогоплательщииков, осуществляющих эти операции, соответствующих лицензий.

Специальных особенностей в НК РФ по определению налогооблагаемой базы по налогу на добавленную стоимость (НДС) для субсидий, предоставляемых бюджетным учреждениям Федеральным законом № 83Ф3 внесено не было. Передача субсидий из бюджета не является операцией, признаваемой объектом налогообложения в соответствии со ст. 146 НК РФ.

Соответственно лимиты бюджетных обязательств, в соответствии с которыми утверждается бюджетная смета, не подлежат включению в налогооблагаемую базу по НДС.

НДС с аренды имущества казенного учреждения. При предоставлении на территории Российской Федерации органами государственной власти и управления, органами местного самоуправления $u$ казеннылми учреждениями в аренду федерального имущества, имущества субъектов Российской Федерации и муниципального имущества налоговая база определяется как сумма арендной платы с учетом налога. При этом налоговая база определяется налоговым агентом отдельно по каждому арендованному объекту имущества. В этом случае налоговыми агентами признаются арендаторы указанного имущества (п.3 ст.161 НК РФ).

Казенные учреждения освобождаются от уплаты государственной пошлины (пп. 1 п. 1 ст. 333.35 НК РФ).

Казенные учреждения так же, как и бюджетные учреждения, не вправе переходить на уплату единого сельскохозяйственного налога и применять упрощенную систему налогообложения (пп. 4 п. 6 ст. 346.2, пп. 17 п. 3 ст. 346.12 НК РФ). Применять упрощенную систему 
DOI: $10.7256 / 1812-8688.2013 .9 .4561$

При цитировании этой статьи сноска на доі обязательна

Налогообложение некоммерческих организаций

налогообложения вправе только автономные учреждения.

Налог на имущество, земельный налог. Автономное и бюджетное учреждение - плательщики налога на имущество и земельного налога. Расходы на уплату налога на недвижимое имущество и особо ценное движимое имущество включаются в сумму субсидии.

Казенные учреждения уплачивают налог на недвижимость и налог на землю за счет доведенных им на эти цели лимитов бюджетных обязательств.

\section{Библиография:}

1. Федеральный закон от 08.05.2010 N 83-Ф3 «О внесении изменений в отдельные законодательные акты Российской Федерации в связи с совершенствованием правового положения государственных (муниципальных) учреждений».

2. Закон РФ от 10.07.1992 N 3266-1 «Об образовании».

3. Налоговый кодекс РФ

4. Бюджетный кодекс РФ. 